\title{
The analysis of marine magnetic field detection influenced by the platform migration
}

\author{
Wang Dan, Chi Cheng \\ Satellite Remote Sensing Military Application Institute \\ Navy submarine academy \\ Qingdao ,China,266000 \\ wangdan-yn@sohu.com; cheng.chihhu@163.com
}

\begin{abstract}
Marine magnetic field detection is influenced by the environment of marine and the platform, The influence of the platform is mainly caused by platform migration.The variation of the geomagnetic field caused by different directions of the platform migration are compared by using the World Magnetic Model WMM2010.We come to the conclusion that the geomagnetic field variation is the biggest in the direction of depth.The conclusion can be used for automatic correction of the marine magnetic field observation platform .
\end{abstract}

Keywords-Marine magnetic field detection,platform migration, WMM2010

\section{INTRODUCTION}

Marine magnetic field detection is an important method to study Marine.The research of the marine electromagnetic field in foreign countries is earlier than in China, and the foreign countries have got a lot of useful conclusions.In 1959, the U.S. researchers D.W.Swift and V.P.Hessler ${ }^{[1]}$ detected the marine electromagnetic field on floating ice in the Arctic Ocean.In 1966, Cox and Larson ${ }^{[2]}$ measured the variation of the marine magnetic field at the seafloor of the Pacific Ocean 600 kilometers from the California coast.The analysis of marine magnetic field detection influenced by the platform migration has not been researched yet.

The special requirements ${ }^{[3]}$ of marine magnetic field detection mainly in terms of special requirements of the instrument.Marine geomagnetic detection platform will migrate due to the complicated Marine environment,So the disturbance of marine magnetic field detection will occur. And the disturbance will impact the results of detection.As the disturbance quantity is calculated,we can use automatic compensation method to correct the measured value,and we can also design the platform with automatic correction.We will strictly control the platform migration to achieve the purpose of accurate measurement.We calculate the variation of the geomagnetic field by using the World Magnetic Model WMM2010.The variations of platforms at 100 meters above the sea surface、 platforms on the sea surface and platforms at 100 meters beneath the sea surface have been calculated.

\section{The World Magnetic Model WMM2010}

The WMM2010 ${ }^{[4]}$ provides the complete geometry of the magnetic field from $1 \mathrm{~km}$ below the Earth' s surface to $850 \mathrm{~km}$ above the surface. the World Magnetic Model (WMM) is produced by the U.S. National Oceanographic and Atmospheric Administration's National Geophysical Data Center (NOAA/NGDC) and the British Geological Survey (BGS). It is the standard model used by the U.S. Department of Defense (DoD), the U.K. Ministry of Defence, the North Atlantic Treaty Organization (NATO) and the International Hydrographic Organization (IHO), for navigation, attitude and heading referencing systems using the geomagnetic field. It is also used widely in civilian navigation and heading systems.

The Earth's magnetism has several sources. All the sources will affect a scientific or navigational instrument but only some of them are represented in the WMM. The strongest contribution is the magnetic field produced by the Earth's liquid-iron outer core, called $\overrightarrow{B_{m}}$. Magnetic minerals in the crust and upper mantle make a further contribution that can be significant locally, the contribution is called $\overrightarrow{B_{c}}$. Electric currents induced by the flow of conducting sea water through the ambient magnetic field make a further, albeit weak, contribution to the observed magnetic field,the contribution is called $\overrightarrow{B_{d}}$, so we come to the conclusion that:

$$
\vec{B}(r, t)=\overrightarrow{B_{m}}(r, t)+\overrightarrow{B_{c}}(r)+\overrightarrow{B_{d}}(r, t)
$$

$\overrightarrow{B_{m}}$ is called the "core field", and the core field is accounted for more than $95 \%$ of the magnetic field intensity of the earth's surface.The geomagnetic field vector, $\overrightarrow{B_{m}}$, is described by 7 elements. These are the northerly intensity $\vec{X}$, the easterly intensity $\vec{Y}$, the vertical intensity $\vec{Z}$ (positive downwards) and the following quantities derived from $\vec{X}, \vec{Y}$, and $\vec{Z}$ : The horizontal intensity $\vec{H}$, the total intensity $\vec{F}$, the inclination angle I, (also called the dip angle and measured from the horizontal plane to the field vector, positive downwards), and the declination angle D (also called the magnetic variation and measured clockwise from true north to the horizontal component of the field vector). 
The main magnetic field is a potential field and therefore can be written in geocentric spherical coordinates( $r$ radius, $\varphi$ latitude, $\lambda$ longitude) as the negative spatial gradient of a scalar potential

$$
\overrightarrow{B_{m}}(\lambda, \varphi, r, t)=-\nabla v(\lambda, \varphi, r, t)
$$

This potential can be expanded in terms of spherical harmonics:

$$
\psi(\lambda, \varphi, r, t)=a\left\{\sum_{n=1}^{N} \sum_{m=0}^{n}\left(g_{n}^{m}(t) \cos (m \lambda)+h_{n}^{m}(t) \sin (m \lambda)(-)_{r}^{a+1} P_{n}^{n}(\sin \varphi)\right)\right\}(3)
$$

where $\mathrm{N}=12$ is the degree of the expansion of the WMM, $\mathrm{a}(6371200 \mathrm{~m})$ is the geomagnetic reference radius, $(\lambda, \varphi, r)$ are the longitude 、 latitude and radius in a spherical geocentric reference frame, and $g_{n}^{m}(t)$ and $h_{n}^{m}(t)$ are the time-dependent Gauss coefficients of degree $\mathrm{n}$ and order $\mathrm{m}$ describing the Earth's main magnetic field. $p_{n}^{m}(\mu)$ are the Schmidt semi-normalized associated Legendre functions defined as:

$$
\begin{aligned}
& P_{n}^{m}(\mu)=\sqrt{2 \frac{(n-m) !}{(n+m) !}} P_{n, m}(\mu) \quad(m>0) \\
& P_{n}^{m}(\mu)=P_{n, m}(\mu) \quad(m=0)
\end{aligned}
$$

And the main magnetic field can be calculated from the equations above.

A step by step procedure is provided below for computing the magnetic field elements at a given location and time ( $\left.\lambda, \varphi, h_{m s l}, t\right)$, where $\lambda$ and $\varphi$ are the geodetic longitude and latitude, $h_{m s l}$ is Mean Sea Level (MSL) height, and $t$ is the time given in decimal years.

First, the user is requested to provide the time, location and MSL height at which the magnetic elements are to be calculated,then the answer will be calculated.and we can download the associated software via the Web at http://www.ngdc.noaa.gov/geomag/WMM/.

\section{THE GEOMAGNETIC FIELD DISTURBANCE SIMULATION}

There are many kinds of marine magnetic field detection platform.According to the location of the platform,the platforms can be divided into aerial platforms,sea surface platforms and undersea platforms.Respectively we will analysis the three heights of 100 meters above the sea surface, 100 meters beneath the sea surface and the sea surface for simulation. The migration of marine magnetic field detection platform can be divided into three kinds:the migration along depth,the migration along latitude and the migration along longitude. We will chose two points for analysis: $\mathrm{A}(24.8333 \mathrm{~N}, 120 \mathrm{E})$ represented the shallow sea point, $\mathrm{B}(21.7167 \mathrm{~N}, 120 \mathrm{E})$ represented the deep sea point.The simulation time is January 2012.The positive direction along depth is upward,the positive direction along longitude is north,the positive direction along latitude is east.Diagram of the simulation results are as follows, $\mathrm{X}$-axis is the offset distance from the original location, in units of meters,y-axis is the change of the earth's magnetic field strength between the original position and the offset position, in units of nT.

Figure 1 to Figure 3 is the change in magnetic field of the point A along depth, latitude and longitude.

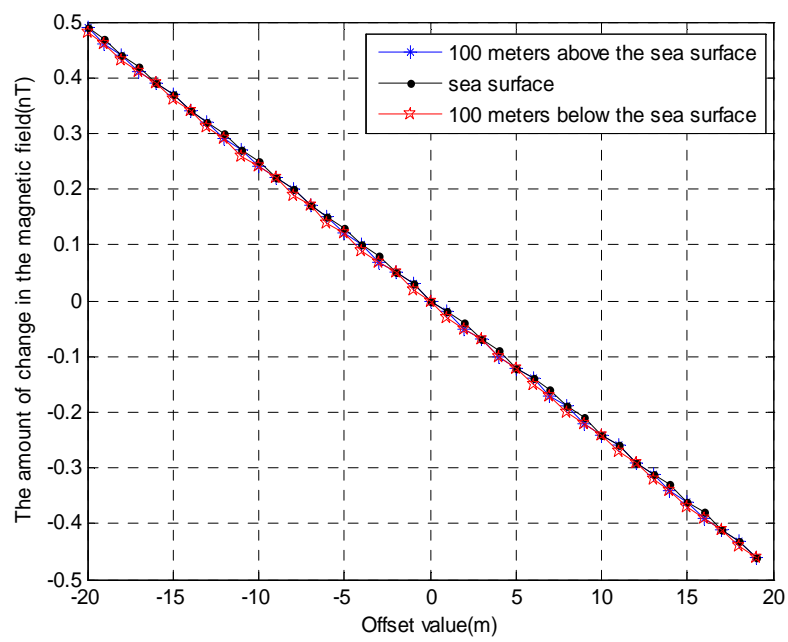

Figure 1 the change in magnetic field of the point A along depth

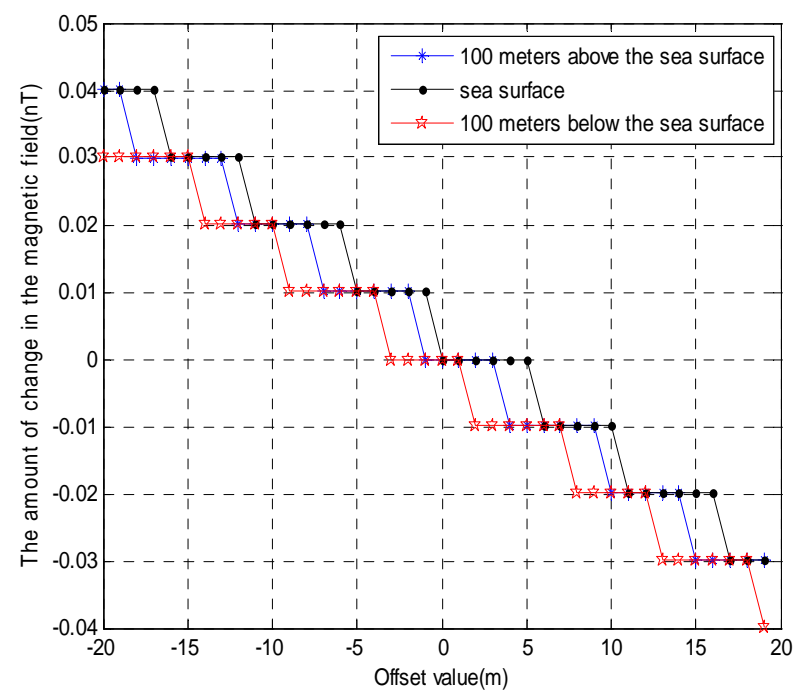

Figure 2 the change in magnetic field of the point A along latitude 


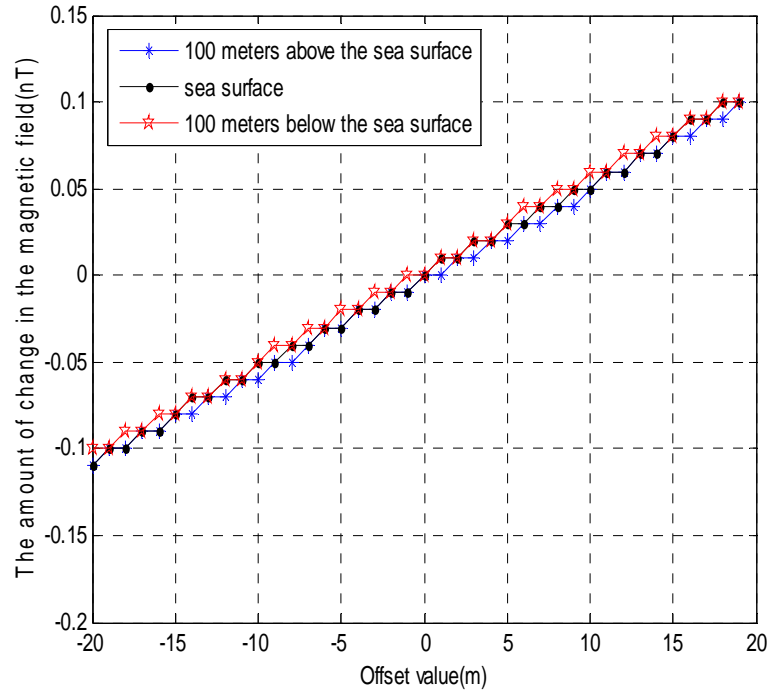

Figure 3 the change in magnetic field of the point B along longitude

Figure 4 to Figure 6 is the change in magnetic field of the point $\mathrm{B}$ along depth, latitude and longitude.

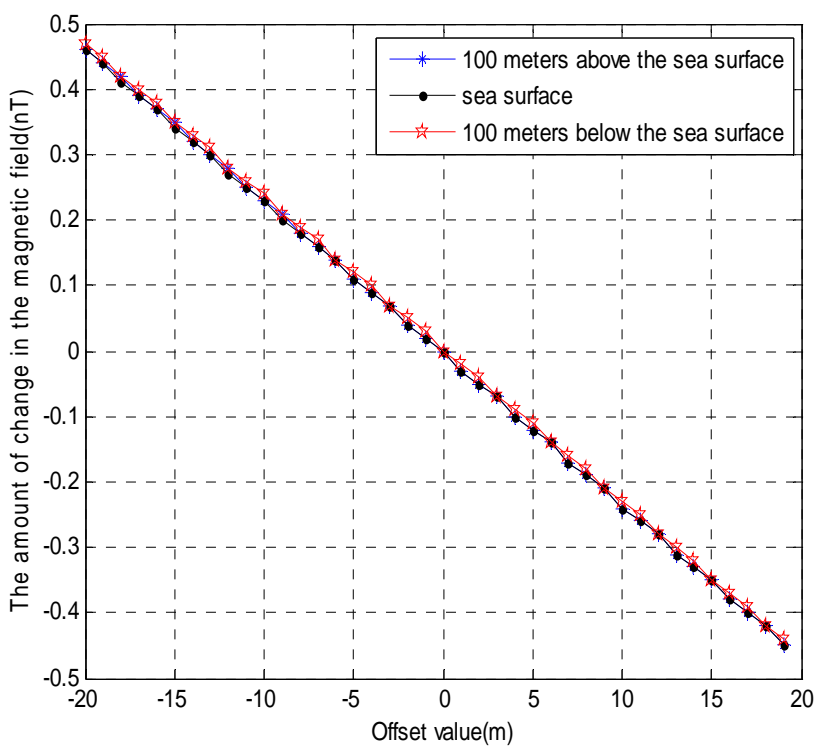

Figure 4 the change in magnetic field of the point $\mathrm{B}$ along depth

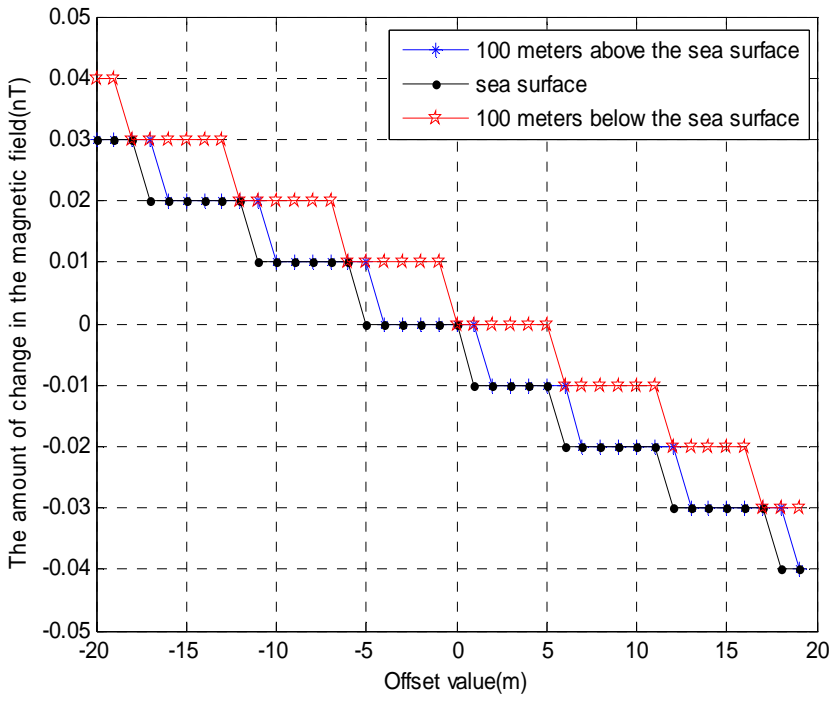

Figure 5 the change in magnetic field of the point A along latitude

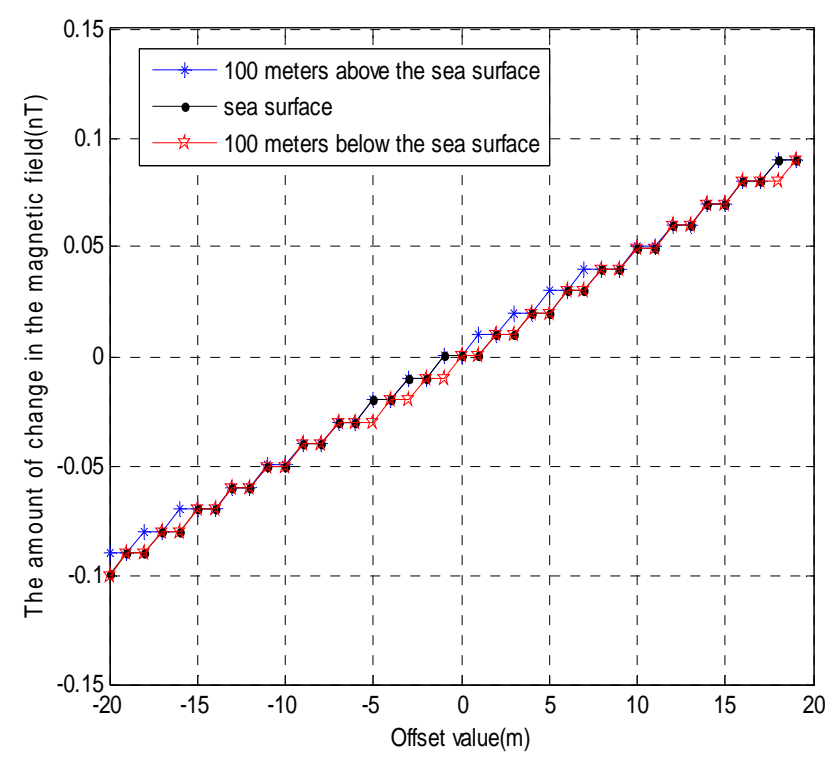

Figure 6 the change in magnetic field of the point A along longitude

The maximum amount of change in the magnetic field caused by A and B respectively shifted 20 meters along the direction of the depth, latitude, longitude are as follows: 


\begin{tabular}{|c|c|c|c|c|c|c|}
\hline \multirow[t]{2}{*}{$\begin{array}{l}\text { direction } \\
\text { type }\end{array}$} & \multicolumn{3}{|c|}{$\begin{array}{c}\text { the shallow sea } \\
\text { point A }\end{array}$} & \multicolumn{3}{|c|}{ the deep sea point $B$} \\
\hline & $\begin{array}{c}100 \\
\text { mete } \\
\text { rs } \\
\text { abov } \\
\text { e the } \\
\text { sea } \\
\text { surfa } \\
\text { ce }\end{array}$ & $\begin{array}{l}\text { sea } \\
\text { surf } \\
\text { ace }\end{array}$ & $\begin{array}{c}100 \\
\text { meter } \\
\text { s } \\
\text { below } \\
\text { the } \\
\text { sea } \\
\text { surfac } \\
\text { e }\end{array}$ & $\begin{array}{c}100 \\
\text { meter } \\
\text { s } \\
\text { above } \\
\text { the } \\
\text { sea } \\
\text { surfa } \\
\text { ce }\end{array}$ & $\begin{array}{c}\text { sea } \\
\text { surf } \\
\text { ace }\end{array}$ & $\begin{array}{c}100 \\
\text { meters } \\
\text { below } \\
\text { the sea } \\
\text { surface }\end{array}$ \\
\hline $\begin{array}{l}\text { Along } \\
\text { depth }\end{array}$ & $\begin{array}{c}0.49 \\
\mathrm{nT}\end{array}$ & $\begin{array}{r}0.4 \\
9 \text { nT } \\
\end{array}$ & $\begin{array}{c}0.48 \mathrm{n} \\
\mathrm{T}\end{array}$ & $\begin{array}{c}0.46 n \\
T\end{array}$ & $\begin{array}{c}0.47 \\
\mathrm{nT}\end{array}$ & $0.47 \mathrm{nT}$ \\
\hline $\begin{array}{l}\text { Along } \\
\text { latitude }\end{array}$ & $\begin{array}{c}0.04 \\
\mathrm{nT}\end{array}$ & $\begin{array}{r}0.0 \\
4 \mathrm{nT} \\
\end{array}$ & $\begin{array}{c}0.04 n \\
T\end{array}$ & $\begin{array}{c}0.04 n \\
T\end{array}$ & $\begin{array}{c}0.04 \\
\mathrm{nT}\end{array}$ & $0.04 \mathrm{nT}$ \\
\hline $\begin{array}{c}\text { Along } \\
\text { longitud } \\
\mathrm{e}\end{array}$ & $\begin{array}{c}0.11 \\
\mathrm{nT}\end{array}$ & $\begin{array}{l}0.1 \\
1 \mathrm{nT}\end{array}$ & $0.1 \mathrm{nT}$ & $\begin{array}{c}0.09 n \\
T\end{array}$ & $\begin{array}{c}0.1 \mathrm{n} \\
\mathrm{T}\end{array}$ & $0.1 \mathrm{nT}$ \\
\hline
\end{tabular}

Table 1 the variation of Geomagnetic field strength caused by offset along three directions

From the Table 1,we can come to the conclusion that the geomagnetic field variation is the biggest in the direction of depth,and the geomagnetic field variation is the least in the direction of latitude. And there are no difference between the deep sea point and the shallow sea point in the the variation of geomagnetic field strength.As the platform shifted 20 meters along the depth,the value of the variation of Geomagnetic field strength will reach 0.5nT.As the platform shifted 20 meters along the longitude,the value of the variation of Geomagnetic field strength will reach $0.1 \mathrm{nT}$.

In order to obtain the relationship of changes of the magnetic field of the different months, we calculate the variation of geomagnetic field strength of the sea surface caused by the offset distance of 20 meters along depth.Diagram of the simulation results are as follows, $\mathrm{x}-$ axis is the month from January 2012 to December 2012, in units of a month,y-axis is the change of the earth's magnetic field strength between the original position and the offset position, in units of nT.

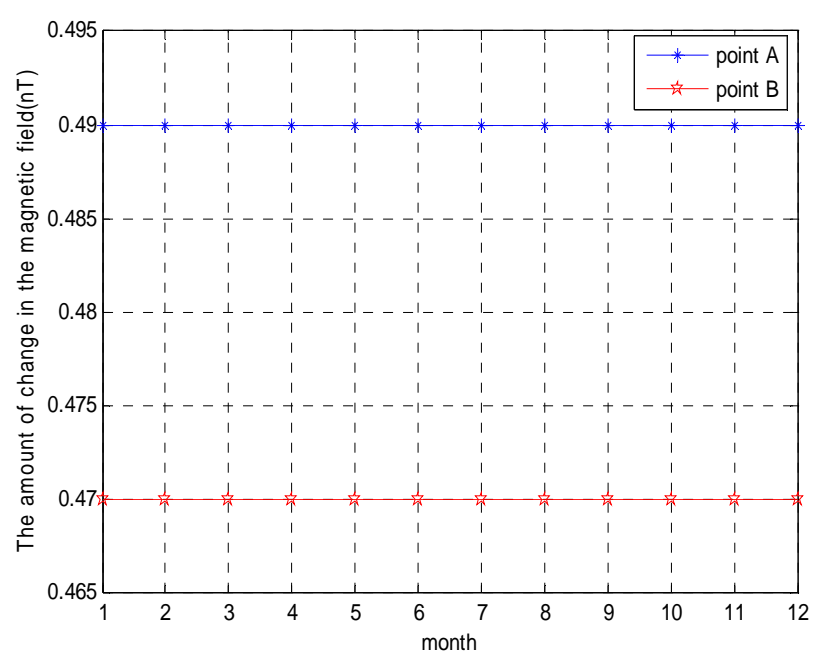

Figure 7 the variation of Geomagnetic field strength in different months

From the Figure 7,we can come to the conclusion that the geomagnetic field variation is the same in different months.

\section{CONCLUSION}

In 2008, Zhang $\mathrm{Zili}^{[5]}$ calculated the electromagnetic field induced by ocean waves.Results show that the electromagnetic field is strongly depends on the period and amplitude of ocean waves.The amplitude of the magnetic field is in level of nT Within 100 meters depth,and the value is similar to the size of the value of change of the magnetic field caused by the offset distance of 20 meters along depth.The geomagnetic change caused by the platform offset is similar to the ocean background noise,so we should take measures to control the attitude of the platform.

The simulation analysis show that the change in the geomagnetic field caused by the disturbance of the platform can not be ignored.the geomagnetic field variation is the biggest in the direction of depth,So the offset in the direction of depth should be strictly controlled.The conclusion can be used for automatic correction of the marine magnetic field observation platform.

\section{REFERENCES}

[1] D. W. Swift, V. P. Hessler A comparison of telluric current and magnetic field observations in the Arctic Ocean[J].J.Geophys.Res 1964,69.

[2] [Cox,Larson. Lunar and solar daily variation in the magnetotelluric field beneath the ocean.Trans.Amer.Geophys.Union,1966,47.

[3] [Chen Yun. The theoretical basis of the natural electromagnetic field in the ocean.Ocean Press. 1987.

[4] Maus, S. , S. Mclean, B Hamilton, A. Thomson, M. Nair. The US / UK World Magnetic Model for2010—2015, NOAA Technical Report NESDIS / NGDC, 2009， 12

[5] Zhang Zili,Wei Wenbo .Theoretical calculation of electromagnetic field generated.Marine Science.2008.1. 